\title{
Research on Accounting Reform and Accounting Information Quality
}

\author{
Ou Liu ${ }^{1,}$, , Haiwen Long ${ }^{1, b}$ \\ ${ }^{1}$ Arts and Sciences College of Yunnan Normal University, Kunming, Yunnan, 650222 \\ ${ }^{2}$ Oxbridge College, Kunming University of Science and Technology, Yunnan University, Kunming, \\ Yunnan, 650106 \\ a email, ${ }^{b}$ email
}

KEYWORDS: Accounting Reform; Accounting Information Quality

\begin{abstract}
In this paper, the reform of joint-stock company accounting system, for example, from the target accounting reform, the use of accounting information market reaction, respectively, from the concept of information and measurement Viewpoint, the quality of accounting information for quantitative research and make its demonstration effect of the reform evaluation, whereby observe reasonable reform of the corporate accounting system. Studies have shown that improving the quality of accounting information accounting reform depends not only on the establishment of high-quality accounting standards, and the reform is inseparable from the implementation of mechanisms to provide effective guidelines for the implementation of the support system.
\end{abstract}

\section{Introduction}

"True and fair accounting information is the market play a decisive role in the allocation of resources in the fundamental guarantee, the government is also important to strengthen market supervision and improve macro-control basis." However, for a long time, the quality of accounting information distortion is not high even been a bottleneck restricting the rapid development of China's economy.

Low levels of relationship quality of accounting information to the user information validity and correctness of economic decision-making related to the capital markets every reasonable allocation of economic resources, but also related to the effective functioning of the social economy. Therefore, how to improve and enhance the quality of accounting information has become the theory and practice to explore the hot spots. Relevant literature on the causes of accounting information quality analysis of the problem a lot together are: inadequate corporate governance, accounting standards system is imperfect, imperfect accounting laws and regulations. The genesis mainly in the areas of system, however, the problem is that the legal system of accounting and accounting management system is relatively sound US accounting scandals information also frequently occurs. Therefore, in order to improve the quality of accounting information, accounting information to prevent the occurrence of distortion, on the one hand to continue to reform the system in the field of defects, on the other hand we should also reflect factors other than those areas system, such as cultural factors. Accounting culture as a "sub-culture" is an important part of socialist culture with Chinese characteristics, China's social culture in the field of accounting to reflect the unique and penetration in the accounting practice from the material, institutional, behavioral and mental four levels activities. Accounting practices of any country deeply marked by 
their specific accounting culture imprint. Accounting information as a special product, is the product of accounting personnel accounting practices, the level is closely related to its level of quality with which the accounting culture.

Standardization of accounting information as a common international language of business information users to make economic decisions of investment or financing, assessing a company's previous forecast future condition or results of operations, improve business management or enterprise an important basis for effective regulation. However, for a long time, the quality of accounting information has been a bottleneck restricting the healthy and stable development of China's economy. Accounting culture is an integral part of social culture, social culture in the field of accounting to reflect unique and it permeates the accounting practice activities.

\section{Research on Accounting Reform}

Accounting information distortion 1 is one of the factors affect our economic order, it is endangering the government's macro decision-making, national tax disturbance, damage the stock market resource optimization function. Given the seriousness of Accounting Information Distortion and Safety, the State Council has attached great importance to the issue of governance of accounting information distortion, issued a series of laws, regulations and measures that can be said that the Government of Accounting Information Distortion problems put a lot of effort and financial resources. Academic accounting information distortion problem has also been given a great deal of attention, but mostly limited to research how to regulate accounting practices, accounting controls for the effect of the lack of quantitative research, and therefore unable to provide evidence of the results of treatment of accounting information distortion, thereby it is difficult to provide policy advice to the government have persuasive authority. In this paper, the reform of joint-stock company accounting system, for example, from an investor's point of view quantitative study on the quality of accounting information to make empirical evaluation of their reform effect, whereby observe reasonable reform corporate accounting system.

According to the information point of view of economics, accounting and financial reporting plays a key role in efficient capital markets. Most accounting standard-setting bodies, for example, the Financial Accounting Standards Board (FASB), the International Accounting Standards Committee (IASC), etc., have adopted investor-oriented concept of decision usefulness of accounting information, and particularly pointed out the purpose of accounting is to meet the capital market need. Although the quality of accounting information related to many factors, it is difficult quantitative characterization, but according to accounting objectives, from an investor's standpoint, the reaction by the market to evaluate the quality of accounting information accounting information regarded as a comprehensive, effective quantitative evaluation methods.

The purpose of accounting reform is to hope that through the implementation of a series of reform policies to improve the quality of accounting information of listed companies to improve the decision usefulness of accounting information, enhanced security market optimize resource allocation functions. So, compared with "pilot joint-stock enterprise accounting system", after the implementation of the "Accounting System Co., Ltd.", is the quality of accounting information has been significantly improved? Under the new system, the A-share companies, short-term impairment of the investment policy, inventory impairment policy and long-term impairment of the investment policy for the voluntary implementation of the policy. Impairment of the implementation of the three water squeezed profits and assets of the company, profits and assets make the data more realistic. So the quality of accounting information, as compared with the three companies did not 
perform an impairment, the impairment of the implementation of the policy of the three companies significantly increased whether it?

For these problems, there is no empirical evaluation, but based on the following reasons, to provide answers to these questions is very necessary. Decision First, it is whether the accounting reform to improve the quality of accounting information, accounting information to improve the usefulness of the evidence provided. Accounting reform goal is to improve the quality of accounting information, enhance decision usefulness of accounting information, optimize the allocation of resources to strengthen the stock market functions, accounting reforms can achieve these targets needs to answer. Secondly, it is reasonable evaluation of "enterprise accounting system" reform trend forecast accounting reform has reference. Because through the perspective effects and problems of the stock market performed accounting reform, we can observe the reasonableness of the current accounting reform, forecast accounting reform to provide evidence. Finally, accounting standards and its value relevance literature has academic value. Reform of Accounting System AG aims to develop high-quality accounting standards, improving the quality of accounting information, accounting information to enhance the value relevance of this test GAAP accounting information on the value of the correlation provides a rare opportunity.

\section{Concept of Accounting Information}

Accounting information is a helpful information economic management and economic decision-making with a broad and narrow sense and broad accounting information from the financial accounting and management accounting information constitutes information. Financial information is provided in the form of financial reporting standards by the accounting information system according to certain operating rules generated information helps users make decisions primarily economic management information expressed in monetary terms. Management accounting information is a non-standard form of internal managers to help them improve or strengthen the operation and management of information, such as various budgets, decision analysis reports, graphs, tables and so on. Accounting information refers only to the narrow financial and accounting information.

\section{Relevant Policy Recommendations about Accounting Reform and Accounting Information Quality}

First, in terms of standard-setting bodies, should consider the introduction of the integration of accounting standards and the economic environment. Effect of shares of the company accounting system reform has not yet fully reflect the reason why, in spite of the problem lies in the lack of enforcement mechanisms and market efficiency, but we should not overlook the fact that the accounting reform given accounting choices and ownership of businesses is too large, and the current economic environment in which companies cannot meet. Accounting reform should reflect the Chinese characteristics, which is the status quo of China's market economy development of the decision. Enterprise Accounting System enacted in 2000 canceled A-share companies the right to choose the eight impairment policy, requiring companies and foreign shares as enforcement of non-monetary transactions and other business processes as much as possible by avoiding the "fair value" pricing, and change the book value recorded. These reforms policy is undoubtedly a wise move considering accounting standards and integration of the economic environment made.

Secondly, in terms of market regulators should actively adopt market-oriented regulatory system and improve the level of supervision and efficiency of the market. Stock Market and the validity of 
the decision usefulness of accounting information complementary, market regulators should try to reduce the extent of induced regulatory policies on corporate earnings manipulation, reduce the regulatory policy and regulatory costs imposed on the company for the effect to play high-quality accounting standards the creation of a liberal market environment. For example, allotment policy, particularly in dealing with policy and suspend trade policy has proven to be a major factor to induce companies to manipulate accounting earnings, the basic reason is that these regulatory policies are the direct basis relative to a single accounting earnings indicators developed and implemented. Since corporate governance is the strict implementation of internal security mechanism of accounting standards, so the market regulators must be regulation of corporate governance structure as a basis for the introduction of the regulatory scope of work, focusing on the source of the information, in order to improve the level and efficiency of information disclosure regulation .

Finally, the government should be actively involved in nurturing and strictly regulate the accounting market intermediaries. Quality of accounting information is closely related with some charged with the supervision and advisory functions of the agency, especially accounting firms and securities investment consulting institutions. If the corporate governance structure is the internal security mechanism the quality of accounting information, the CPA audit and supervision of the quality of accounting information it is the external protection mechanisms, a practicing CPA in quality to some extent determine the quality of accounting information. In the West the stock market, financial analysts on the effectiveness of the market plays a key role, because it is through the financial market analysts such professional investment advisory intermediary, timely and accurate delivery and interpret a variety of information about the company (including accounting information), between the investor and the company set up a bridge of communication and information, so that the stock price can appropriately reflect the company's intrinsic value, improve market efficiency of resource allocation optimization. These two agencies in our country is not lacking, but the feature is not yet in place, especially in all kinds of securities advisory body, the work and the role and functions of financial analysts played by far.

\section{Conclusion}

Accounting information as a result of accounting practices is the product of accounting personnel behavior. Thus, accounting information can be regarded as a special product. The quality of accounting information is reflected in the formation process of accounting information in line with accounting standards and to meet the requirements of the degree of information the user needs. Accounting information for users of the information is true and reliable, whether the relevant decision, whether to disclose in a timely manner, etc. to measure the quality of accounting information level. Is true and reliable, with economic decision-making, and timely disclosure of accounting information is of high quality accounting information.

\section{REFERENCE:}

[1] Suzi. The culture and improve the quality of accounting information Accounting [J]. Accounting Forum, 2007,23-24

[2] Min Zhou. The culture and improve the quality of accounting information accounting [J]. Accounting Research, 2011,259

[3] Jia Jun. Strengthen the construction of cultural tectonics Accounting Credit [J]. Modern Economic Information, 2010,100 
[4] Zhu Yumeng. The corporate culture Accounting: Accounting Information Distortion flexible constraining mechanism [J]. Economic Research, 2012,50

[5] Liu Yan. The accounting impact of culture on the Quality of Accounting Information [J]. Accounting and Taxation, 2012,11 